\title{
Personal Knowledge Management And Student Learning
}

Stuart Garner, Edith Cowan University, Western Australia

\begin{abstract}
Students who undertake courses of study at colleges and universities are generally more successful in their learning outcomes if they are able to manage their personal knowledge well and effectively. This paper begins by discussing the meaning of personal knowledge management (PKM) and how it relates to teaching and learning, particularly to a commonly used instructional design framework. Some of the electronic tools that students might utilise are then discussed. Finally several electronic tools that might prove useful to students to aid their PKM are suggested.
\end{abstract}

Keywords: Personal knowledge management

\section{INTRODUCTION}

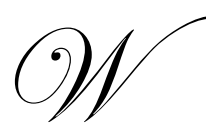

ith the rapid changes in the use of technology, student learning has changed as there is a need for students to collect information from multiple resources. That information then has to be transformed into knowledge by each student. Because of the vast amounts of information that students collect when learning, there is a need for them to organise their materials in a sensible manner, in effect managing their personal knowledge. This paper discusses what personal knowledge management (PKM) is and how it is associated with student learning. Some of the electronic tools that might be used to help student PKM are then discussed.

\section{WHAT IS PERSONAL KNOWLEDGE MANAGEMENT (PKM)?}

It is difficult to define knowledge accurately, however it is generally agreed that knowledge is an organised combination of ideas, rules, procedures and information [1]. When students learn, they gather information and then construct knowledge based on the knowledge that they already have. They are constantly adjusting their internal schemata and mental models as they transform information into knowledge. This is why constructivism is so important in teaching and learning as tutors look to ways to help students construct knowledge in the subject that is being "learnt" $[3,11]$. Students have to make "meaning" of the information that they gather and by doing so the disorganised information becomes knowledge [4]. It is only through meaning that information finds life and becomes knowledge.

The more successful students are usually very adept at managing their own personal knowledge. With respect to PKM:

"Individuals need to know how to decide on and seek out new and relevant information, knowledge, experiences and "learnings". " [9].

With respect to PKM, Norton and Sprague state that:

"Today, all of us live and learn in a world that has been radically altered by the ready availability of vast stores of information encoded in a variety of formats. The learning process and the information process mirror each other as we seek to construct meaning from the sources we encounter and to create products that shape and communicate meaning effectively. Developing expertise in organizing and analyzing information is in fact the authentic learning that modern education must promote." [8]. 
It is suggested that there are seven components of PKM [2]: (1) retrieving information; (2) evaluating/assessing information; (3) organising information; (4) analysing information; (5) presenting information; (6) securing information; and (7) collaborating around information.

\section{PKM AND TEACHING AND LEARNING}

In order to understand the association between PKM and learning, it is helpful to make use of a learning framework as this can clarify the sources of information and the tasks that students commonly undertake. A generic learning framework has been proposed by Oliver and Herrington [10] which is heavily influenced by the belief that constructivism best describes how learning takes place. The framework comprises three critical elements: learning resources (content); learning activities; and learning supports.

Learning resources provide the content for a course and can be thought of as the materials which are used to help students construct their knowledge and meaning with respect to a domain of knowledge. Learning activities play a fundamental role in determining learning outcomes [14]. The activities determine how learners engage with the various materials and well designed activities can help reduce the extraneous cognitive load that students experience and help students develop their personal knowledge. Learning supports can be thought of as the supports required to help guide and provide feedback to learners in a way that is responsive and sensitive to learner individual needs [5]. In technology based learning environments, such supports are often known as "scaffolds" and they help learners during their knowledge construction process [12]. Often this involves tutors attempting to make their tacit knowledge explicit and available to students.

The seven components of PKM can be mapped onto the learning framework. Students usually learn best by carrying out activities that require them to interact with content and produce some form of solution to an activity. An activity is often in the form of an assignment that would frequently be carried out in a group with other students. The assignment might require a model or report to be produced and a presentation to be made to other students.

A student might start an activity by carrying out the first three elements of PKM: 1) Retrieving content / information from books, lecture notes, web sites, journal papers, etc; 2) Evaluating/assessing information which involves judging the quality of information and determining its relevance to the activity; and 3) Organising the information gathered which is often done by keeping paper based notes or storing notes as text in a Word document.

The fourth element of PKM, analysing information, is generally where the "problem" set in the activity is "solved" and entails the challenge of "tweaking" meaning out of data [2]. Here, learner supports may well be needed in the form of electronic student scaffolds, interaction with other students, and feedback to queries, drafts etc from a tutor.

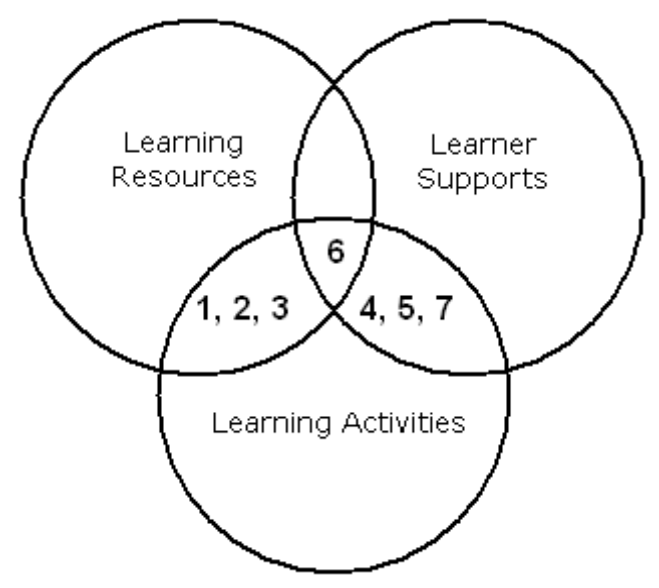

Figure 1: Learning Framework [10], with the Seven PKM Elements 
The analysis of information is enhanced by students working in groups and discussing a problem / activity. The seventh element of PKM is relevant to this as students are collaborating around information and groupware can enhance this experience. The collaboration usually results in the output of an assignment which corresponds to the fifth PKM element, presenting information.

Finally, the sixth PKM element, securing information, is important throughout a student activity as all the digital data in the form of various documents needs to be secured and backed up, something which students are notoriously bad at. The seven PKM elements are shown mapped to Oliver's framework in Figure 1.

\section{TOOLS FOR USE WITH PKM AND LEARNING}

There is a variety of electronic tools that can be used by students to support their PKM and learning and some that have been used by the author with students at an Australian university are discussed here.

Students often receive assignments and "handouts" electronically and usually these are in the form of Word or Adobe Acrobat format documents. Students generally store these in an appropriate folder on the hard disk of their computer. Students also need to store various notes concerning their learning. Such notes come from multiple sources and may be conversations copied from discussion boards; emails that they have received; copies of certain paragraphs from web pages; notes on group meetings; etc.

A particularly versatile tool for storing and manipulating such notes and information is Microsoft OneNote. Microsoft [6] state that:

You can be as organized or as haphazard as you like with your pages of notes. If you like to organize information by storing it in separate categories, you can create several sections and folders, each with its own purpose. If you have a more freeform style, OneNote has several other features that make it easy for you to find your notes regardless of how they are organized.

OneNote also has facilities for simple diagramming and for recording audio notes. A typical page is shown in Figure 2.

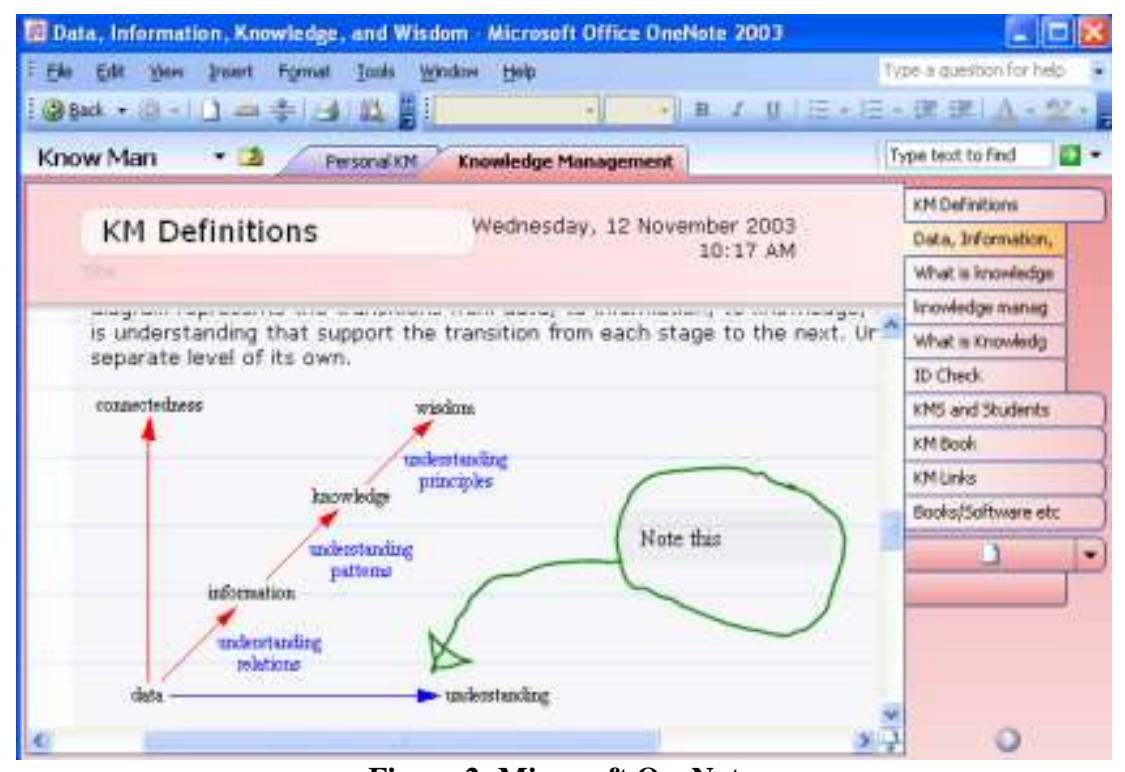

Figure 2: Microsoft OneNote 
After receiving an assignment or task from their tutor, then PKM component 1, retrieving information, is undertaken. Search engines such as Google are often used to search for relevant information. PKM component 2, evaluating/assessing information, then takes place as students decide what is relevant to the problem in hand. Useful and relevant information is then organised and saved, this being PKM component 3 . This information is often in the form of web page sections; text from newsgroups; text from electronic journals; etc. Tools to store such information include: Microsoft OneNote; Adobe Acrobat, which allows Web sites to be stored; web site copiers such as WinHTTrack; and Endnote, which is a referencing tool that also allows notes in the form of text to be stored.

PKM component 4 is where the analysis of all the relevant information takes place and where the "problem" gets solved. OneNote is again useful here as downloaded web pages and notes can easily be annotated and highlighted to help in the problem solving process. Other useful tools include mind mapping tools such as MindManager [7] to help organise the data and facilitate problem solving.

A problem solution needs to be presented and this is done in PKM component 5. The main tools used are usually: a word processor such as Microsoft Word; and presentation software such as Microsoft Powerpoint.

Many student assignments are carried out in groups and the PKM components 4 and 5 might therefore require students to collaborate around the information, this being PKM component 7 . Students may use such tools such as: Internet chat; email; and group discussion boards.

The backing up and securing of information, PKM component 6, can be problematic for students and this is exacerbated by the fact that the information that they have retrieved and organised may be in different files and folders. There are good backup tools available, including that provided in Microsoft Windows, but they are not always easy to use. The fact that cheap flash memory is now widely available in the form of thumb drives should help in this area, assuming that students can be persuaded of the importance of securing data.

\section{DISCUSSION}

Students who are well organised and manage their personal knowledge well generally achieve higher grades than those who do not [13]. This paper linked the 7 PKM components identified by Dorsey [2] with a learning framework developed by Oliver [10]. Some of the tools that can be used by students to support their PKM and learning were discussed. In the author's opinion, one of the most useful tools to help students manage their knowledge is OneNote. However other tools are required to address all 7 of the PKM components. Perhaps one of the challenges for software developers is to produce a truly integrated suite of tools to support PKM and learning.

\section{REFERENCES}

1. Dalkir, K. (2007) Knowledge management in theory and practice, Butterworth-Heinemann.

2. Dorsey, P. (2003). What is PKM? Available: http://www.docstoc.com [2010, 7 Feb 2010].

3. Jonassen, D. H. and Reeves, T. C. (1996) In Handbook of research on educational communications and technology (Ed, Jonassen, D. H.) Macmillan, New York, pp. 693-719.

4. Marakas, G. M. (1999) Decision Support Systems in the Twenty-first Century, Prentice Hall, Englewood Cliffs, NJ.

5. McLoughlin, C., \& Oliver, R. (1998). Scaffolding Higher Order Thinking In A Telelearning Environment. Paper presented at the Ed-Media/Ed-Telecom 98 World Conference On Educational Multimedia And Hypermedia \& World Conference On Educational Telecommunications, Virginia.

6. Microsoft (2010). Get started with Microsoft Office OneNote 2007. Available: http://office.microsoft.com/en-gb/onenote/HA100325211033.aspx [2010, 11 Feb 2010].

7. MindManager (2010). Stop Over-Communicating, Start Collaborating: Introducing Mindjet Catalyst. Available: http://blog.mindjet.com/2009/10/stop-over-communicating-start-collaborating-introducingmindjet-catalyst [2010, 4 Jan 2010].

8. Norton, P., \& Sprague, D. (2000). Technology for Teaching: Pearson, Allyn \& Bacon.

9. Pauleen, D. (2009). Putting the "person" back into the knowledge equation, Online Information Review, Emerald. 
10. Oliver, R. and Herrinton, J. (2001). Teaching and Learning Online, Centre for Research in Information Technology and Communications.

11. Ring, G. and McMahon, M. (1997) In International Conference in Computers in Education '97, Kuching, Malaysia, pp. 220-228.

12. Roehler, L. R., \& Cantlon, D. J. (1996, May 10th 1996). Scaffolding: A Powerful Tool in Social Constructivist Classrooms. Available: http://www.educ.msu.edu/units/literacy/paperlr2.htm [1998, 3 May 1998].

13. Seven Habits Of Highly Successful Students (2010). Available: www.uni.edu/advising/academic/resource/newfresh_handbook.pdf [2010, 3 Feb 2010].

14. Wild, M., \& Quinn, C. (1997). Implications of educational theory for the design of instructional multimedia. British Journal of Educational Technology, 29(1), 73-82. 
NOTES 